\title{
CEPHALIC INDEX IN NEWBORNS: THE EFFECT OF HEREDITY AND SEX
}

\author{
Aprajita Sikka1, Subhash Kaushal2, Patnaik Vantharam Venlata Gopichand ${ }^{3}$ \\ ${ }^{1}$ Associate Professor, Department of Anatomy, Christian Medical College and Hospital, Ludhiana. \\ 2Professor, Department of Anatomy, Government Medical College and Rajindra Hospital, Ludhiana. \\ 3 Professor, Department of Anatomy, Mullana Institute of Medical Sciences and Research, Mullana, Ambala.
}

\section{ABSTRACT}

Anthropometric dimensions are the basis of evaluation of health of new-borns.

\section{MATERIALS AND METHOD}

Head length and Head Width of three hundred sixty normal new-borns (180 male and 180 female) belonging to three different endogamous groups, i.e. Jat Sikhs, Banias and Majhbi Sikhs were recorded and Cephalic Index was calculated.

\section{RESULTS}

The difference in mean Cephalic index was found to be highly significant in the three endogamous groups $(\mathrm{p}<0.001)$, whereas it was just significant in males and females.

\section{CONCLUSION}

Cephalic index varies with heredity and also shows sexual dimorphism. This variation can be used in forensic practice for identification of skeletal remains. It is also useful in plastic surgery, facial reconstruction, pediatrics, oral surgery, dentistry and various other craniofacial surgeries.

\section{KEYWORDS}

Anthropometry, Cephalic Index, Endogamous Groups, Heredity, Sexual Dimorphism.

HOW TO CITE THIS ARTICLE: Sikka A, Kaushal S, Gopichand PVV. Cephalic index in new-borns: the effect of heredity and sex. J Evolution Med Dent Sci 2016;5(1):27-29, DOI: 10.14260/jemds/2016/7

\section{INTRODUCTION}

Body proportions and absolute dimensions vary widely with respect to age and sex within and between racial groups. While this is partly due to variability in muscularity and adiposity; such variations are chiefly skeletal; their study is anthropometry.[1,2]

Race, sex, nutritional status and cultural factors affect craniofacial measurements. Out of these sex is a major factor. ${ }^{[3]}$ Climate and geographical regions also influence head dimensions. [4,5] With respect to variation of head shape in various races and geographical zones, it was observed that hereditary factors primarily affect the shape of head, however environment has secondary effect on it.[6] Shape of vault is not directly related to the cerebral growth, but to genetic factors. This is supported by great range of cranial indices and shapes in racial groups, however sexual differences are minimal.[7]

The adaptation of anthropometry for use in medicine has led to improvements in technique of measurements and in location of landmarks, modifications of standard measurements and development of new ones.[8] Craniometric measurements have a special usefulness in forensic practice where cranial remains can be compared with existing photographic and radiological records in making the identification. ${ }^{[9]}$

Financial or Other, Competing Interest: None.

Submission 11-12-2015, Peer Review 12-12-2015,

Acceptance 29-12-2015, Published 02-01-2016.

Corresponding Author:

Dr. Aprajita Sikka,

Department of Anatomy,

Christian Medical College,

Ludhiana.

E-mail: aprajitasatija@gmail.com

DOI:10.14260/jemds/2016/7
Anthropometric measurements serve as useful adjuncts to other observations in evaluating intrauterine as well as infant growth and development.[10,11] Dimensions of newborn's body can be the basis for all changes in anthropometric indices. These dimensions are important in this field, because this is one of the new-born health evaluation indices. ${ }^{[6]}$

There is scarcity of data regarding measurement of these indices in new-borns. Although some anthropometric studies of new-borns have been carried out in other parts of the world, studies on cephalometry have not been carried out in Northern part of India. Also, there is scope for research in various geographical and racial groups. The purpose of our study was to provide a baseline data for Cephalic Index in different endogamous groups and to observe sexual dimorphism, if any in the region around Patiala in Punjab.

\section{MATERIALS AND METHOD}

The present study was conducted on 360 normal new-borns born at different gestational ages in Government Medical College and Rajindra Hospital, Patiala. All neonates belonged to similar socioeconomic status to further decrease the effect of external factors and to make the study highly specific. The three endogamous groups taken into consideration were Jat Sikhs, Banias and Majhbi Sikhs. One hundred twenty newborns from each group were selected. Further there were an equal number of male and female neonates (i.e. 180 males and 180 females).

Babies with craniofacial abnormalities (Such as cleft palate, cleft lip, micrognathia, caput succedaneum, cephalhematoma, hydrocephalous, etc.) were excluded.

The various measurements were taken with Martin spreading calipers after taking an informed consent from the parents or the guardians. 
Cephalic Index was calculated as a proportion of head width to head length expressed as a percentage as follows:

Cephalic index $=\underline{\text { Head width X } 100}$ Head length

Where Head width is the greatest breadth at right angles to the median plane.

Head length is the distance between glabella and the farthest occipital point.

The morphological classification of Cephalic Index is as follows.[6]

\begin{tabular}{|c|c|}
\hline Head Shape & Range of Cephalic Index (\%) \\
\hline Dolichocephalic & Upto 74.9 \\
\hline Mesocephalic & $75.0-79.9$ \\
\hline Brachycephalic & $80.0-84.9$ \\
\hline Hyperbrachycephalic & $85.0-89.9$ \\
\hline \multicolumn{2}{|c|}{ Table 1 } \\
\hline
\end{tabular}

All measurements were taken within 24 hours of birth and were taken and recorded by the same observer throughout the study. The data for each new-born was recorded in a special form, compiled and then analysed statistically. The student's ' $t$ ' test and discriminant function analysis were used for statistical analysis.

\section{OBSERVATIONS}

Data from 360 neonates was grouped under three endogamous groups-Jat Sikhs $(n=120)$, Banias $(n=120)$ and Majhbi Sikhs $(\mathrm{n}=120)$.

\begin{tabular}{|c|c|c|c|c|c|c|}
\hline & \multirow{2}{*}{$\mathbf{n}$} & \multirow{2}{*}{ Mean } & \multicolumn{2}{|c|}{ Range } & \multirow{2}{*}{ S.D. } & \multirow{2}{*}{ C.V. } \\
\cline { 4 - 5 } & & & Min & Max & & \\
\hline $\begin{array}{c}\text { Jat Sikhs } \\
\text { (JS) }\end{array}$ & 120 & 82.10 & 77.60 & 85.86 & 1.78 & 2.17 \\
\hline Banias(B) & 120 & 78.10 & 73.83 & 82.52 & 1.40 & 1.79 \\
\hline $\begin{array}{c}\text { Majhbi } \\
\text { Sikhs (MS) }\end{array}$ & 120 & 79.30 & 75.96 & 82.57 & 1.29 & 1.63 \\
\hline
\end{tabular}

Table 2: Cephalic Index in Different Endogamous Groups (Jat Sikhs, Banias, Majhbi Sikhs)

(Where $\mathrm{n}$ is number, min. is minimum, max is maximum, S.D. is for standard deviation and C.V. is for coefficient of variation).

JS and B: $p<0.001$ (Highly Significant)

JS and MS: $p<0.001$ (Highly Significant)

B and MS: $p<0.001$ (Highly Significant)

Table 2 shows that in a study of 360 neonates belonging to three different endogamous groups, the mean Cephalic Index is $82.10 \pm 0.16$ in Jat Sikhs, $78.10 \pm 0.13$ in Banias and $79.30 \pm 0.12$ in Majhbi Sikhs. On statistical analysis the difference is statistically highly significant $(\mathrm{p}<0.001)$ among the three endogamous groups. The head form is Mesocephalic in Banias and Majhbi Sikhs whereas it is Brachycephalic in Jat Sikhs.

\begin{tabular}{|c|c|c|c|c|c|c|}
\hline & \multirow{2}{*}{$\mathbf{n}$} & \multirow{2}{*}{ Mean } & \multicolumn{2}{|c|}{ Range } & \multirow{2}{*}{ S.D. } & \multirow{2}{*}{ C.V. } \\
\cline { 4 - 5 } & & & Min. & Max. & & \\
\hline Males & 180 & 80.07 & 74.07 & 85.86 & 2.43 & 3.03 \\
\hline Females & 180 & 79.61 & 74.55 & 84.76 & 2.07 & 2.60 \\
\hline
\end{tabular}

Table 3: Cephalic Index In Males and Females
Table 3 shows that the mean Cephalic index of males $(80.07 \pm 0.18)$ is higher than that of females $(79.61 \pm 0.15)$ and this difference is statistically just significant $(\mathrm{p}<0.05)$.

\section{DISCUSSION}

Indices of human head and face morphology and derived indices are the main sources of head and facial characteristics that influence human appearance, and are the main basis for recognizing individual's Anthropometric measurements are useful indicators in a population to determine the sexual and racial differences. The Cephalic Index, in particular, is most often utilized for the change in trend of population, which is further influenced by internal and external factors.

In the present study when taken irrespective of race, the dominant head form is mesocephalic, but the endogamous group differentiation is evident and this shows that the shape of head depends on hereditary factors.

In a study in Iran, the difference in Cephalic index in the two races of Iran, i.e. Turkman and Fars is non-significant. [6,12] However, on comparison with studies on adults in India, significant differences have been observed in Cephalic Index in different endogamous groups.

At the time of birth, Mesocephaly dominated in Banias, Brachycephaly in Jat Sikhs and Dolichocephaly in Majhbi Sikhs. When this data is compared with adults, it seems that Dolichocephaly is the dominant head form of this region.[13,14,15] It can be observed that there occurs dolichocephalization in Jat Sikhs and Banias with age, whereas in Majhbi Sikhs there is no change in shape of head.

The variation in mean Cephalic Index in males and females was found to be just significant. Golalipour et al. $(2003,2005)$ observed higher values in females.[6,12]

The problem; at what age, sex differences appear is of great interest. It is a known fact that sexual dimorphism appears during puberty. In the present study, the data suggests that sex differences are present at the time of birth. Therefore, these differences have to appear during fetal development.

Cephalometric study is also important in forensic science for the facial reconstruction of disputed identity.[16] It has also been applied in oral surgery concerned with craniofacial deformity.[17] It enables quantitative description that is more precise and objective than the current practice of sole reliance on visual impression. Anthropometric studies have been found useful in craniofacial surgery, otorhinolaryngology and syndromology. Perhaps by joining talents, physical anthropometrists and medicine and surgical clinicians will advance the field and improve patient care. ${ }^{[8]}$

This study demonstrates that Cephalic index is determined by genetic and racial factors. Also, sex characters appear during fetal development. It is suggested that efforts are necessary for determining the role of heredity, environment, ageing, sex and racial factors on the shape of head, especially in new-borns. This study can serve as a baseline study and can provide useful criteria for future anthropometric studies. 


\section{REFERENCES}

1. Martin R. Lehrbuch der Anthropologie. 3rd 2nd ed Fischer: Jena. Cited from Williams and Warwick; The skeletal system in Gray's Anatomy. 38th ed. London ELBS with Churchill Livingstone Edinburgh; 1998 p.434.

2. Hrdlicka A. Practical anthropometry. Wistar Institute, Philadelphia, 1939. Cited from Williams and Warwick; The skeletal system in Gray's Anatomy. 38th ed London ELBS with Churchill Livingstone Edinburgh; 1998 p.433.

3. Sharma K. Sex differences in genetic determinants of craniofacial variations-a study based on twin kinships. Acta Genet med Gemellol (Roma) 1998;47(1):31-41.

4. Weninger M. As to the influence of climate on head form. Anthropol Anz 1979 Jan;37(1):18-26.

5. Bharati S, Som S, Bharati $P$, et al. Climate and head form in India. Am J Hum Biol 2001;13(5):626-34.

6. Golalipour MJ, Haidari K, Jahanshahi M, et al. The shapes of head and face in normal male new-borns in South East of Caspian Sea (Iran-Gorgan). J Anat Soc India 2003;52(1):2831.

7. Farkas LG. Accuracy of anthropometric measurements: past, present and future. Cleft Palate and Craniofacial Journal 1996 Jna; 33(1):10-22.

8. Stewart TD. Evaluation of evidence from the skeleton. In: Gradwohl REH (ed) Legal Medicine. St. Louis: Mosby; 1954.p.407-50. Cited from Krogman WM. Sexing skeletal remains. In the human skeleton in forensic medicine. Springfield, Illinois, USA: Charles C. Thomas; 1962.p.11251.

9. Lubchenco LO, Hansman C, Boyd E. Intrauterine growth in length and head circumference as estimated from live births at gestational age from 26 to 42 weeks. Pediatrics 1966;37(3):403-8.
10. Bhat GJ, Mukelabai K, Shastri GN, et al. Anthropometric parameters of Zambian infants at birth. J Trop Pediatrics 1989;35:100-4.

11. Golalipour MJ, Jahanshahi M and Haidari K. The variation of head and face shapes in female new-borns in South East of Caspian Sea (Iran-Gorgan). Eur J Anat 2005;9(2):95-8.

12. Bhargava I and Kher G. An anthropometric study of Central India, Bhils of Dhar district of Madhya Pradesh. J Anat Soc India 1960;9(1):14-9.

13. Singal P, Sidhu LS. A study of cephalo-facial measurements from age 20 to 80 in Jat Sikh and Bania females of Punjab (India). Anthropol Auz 1986;44(4):361-7.

14. Balgir RS. Bioanthropometric diversity among the breeding isolates of Gujjars in North-Western India. South Asian Anthropologist 1999;20(1):19-25.

15. Lubchenco LO, Hansman C, Boyd E. Intrauterine growth in length and head circumference as estimated from live births at gestational age from 26 to 42 weeks. Pediatrics 1966;37(3):403-8.

16. Rabey GP. Morphanalysis. London: Lewis;1968. Cited from Roger WS, editor Skeletal system. In: Williams PL, Bannister LH, Berry MM, Collins P, Dyson M, Dussek JE, et al. editors. Gray's Anatomy- The anatomical basis of medicine and surgery 38th ed. London ELBS with Churchill Livingstone Edinburgh; 1998 p.612.

17. Ll Yong Lan, Zheng LianBin, Yu KeLi, Lu ShunHua, Zhang XingHua, LiYu Ling, et al. Variation of head and facial morphological characteristics with increased age of Han in Southern China. Chinese Science Bulletin Feb 2013; 58 (4-5):517-24. 